Revista de

Contabilidade e

Organizações
DOI: http://dx.doi.org/10.11606/rco.v7i18.55613
Journal of

Accounting and

Organizations

\title{
Separação entre propriedade e controle e sua relação com desempenho e valor de empresas brasileiras: onde estamos?
}

\author{
Fernanda Maciel Peixoto ${ }^{a}$; Aline Rabelo Assis Buccini ${ }^{b}$ \\ ${ }^{a}$ Universidade Federal de Uberlândia \\ ${ }^{b}$ Universidade Federal de Minas Gerais
}

\section{Informações do Artigo}

Histórico do Artigo

Recebido: 02 Abril 2013

Aceito: 04 Outubro 2013

Palavras chave

Estrutura de Propriedade e Controle Desempenho

Valor

\begin{abstract}
Resumo
Inicialmente, esta investigação realiza um diagnóstico da situação atual da estrutura de propriedade e controle das empresas brasileiras de capital aberto negociadas na Bolsa de Valores de São Paulo nos anos de 2004, 2006 e 2008. Em seguida, busca identificar uma possível relação entre a concentração de direitos de voto e a concentração de direitos sobre o fluxo de caixa com desempenho e valor das empresas. Para tanto, utiliza a análise de dados em painel visando relacionar variáveis de estrutura de propriedade e variáveis de desempenho/valor (Q de Tobin, Retorno sobre o Ativo e Price to Book Ratio). Como resultados, percebeu-se que no Brasil ainda há alta concentração de controle em poder de poucos acionistas. No entanto, o percentual de empresas com esse perfil vem diminuindo no período estudado. A razão capital votante sobre capital total também vem se reduzindo, o que é positivo para a governança corporativa. Os acionistas de empresas familiares, de empresas de capital privado e estatais vêm perdendo espaço na composição acionária das organizações, dando lugar aos acionistas institucionais, estrangeiros e acionistas pulverizados. No que tange à relação entre estrutura de propriedade e valor/performance, constatou-se que firmas com estrutura mais concentrada possuem menor valor e menor desempenho.
\end{abstract}

Copyright (C 2013 FEA-RP/USP. Todos os direitos reservados

\section{INTRODUÇÃO}

Suponha que determinada empresa deseja modificar sua estrutura de propriedade e de controle, mantendo outros aspectos corporativos inalterados. Essa decisão irá afetar seu valor de mercado e desempenho corporativo? De que forma? Empresas que apresentam menor concentração de propriedade e/ou controle mais disperso revelam desempenho melhor ou pior? Este artigo busca responder essas questões, investigando uma possível relação entre estrutura de propriedade e desempenho/ valor. Dessa forma, o objetivo deste estudo é analisar a evolução da estrutura de propriedade e controle de empresas de capital aberto negociadas na Bovespa, nos anos de 2004, 2006 e 2008, e possíveis desdobramentos de mudanças nessa estrutura sobre o desempenho da amostra analisada.

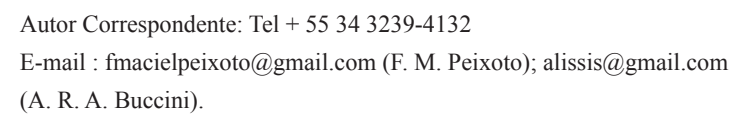

Universidade Federal de Uberlândia. Av. João Naves de Ávila, no 2121 Santa Mônica 38400902 - Uberlandia, MG - Brasil
As principais hipóteses deste estudo são: a) há relação inversa entre o direito de controle detido pelo acionista controlador e a melhoria no desempenho empresarial; e b) há relação positiva entre o direito sobre o fluxo de caixa detido pelo acionista controlador e a melhoria no desempenho empresarial. Para testar essas hipóteses, inicialmente, procedeu-se a um diagnóstico da atual estrutura de propriedade e controle das empresas de capital aberto negociadas na Bovespa. Em um segundo momento, utilizou-se Análise de Dados em Painel visando relacionar a estrutura de propriedade e controle com o desempenho das empresas objeto de estudo.

Como resultados, constatou-se que no contexto nacional ainda há alto nível de concentração de controle e propriedade em poder do acionista majoritário. No entanto, a razão capital votante sobre capital total (denominada neste estudo de alavancagem da posição acionária) vem se reduzindo, o que é positivo em termos de governança corporativa. A composição acionária demonstrou mudanças estruturais, já que os acionistas de empresas familiares, de empresas de capital privado e estatais vêm perdendo espaço para os acionistas institucionais, estrangeiros e pulverizados. No que tange à relação entre estrutura de propriedade e desempenho, observou-se que estruturas mais concentradas estão 
associadas a menor performance e menor valor da firma. Tais resultados são coerentes com a literatura sobre o tema (CARVALHAL-DA-SILVA; LEAL, 2006; SILVEIRA, 2004).

É importante esclarecer que, segundo a Lei $\mathrm{n}^{\circ}$ 6.404/76 (Lei das Sociedades por Ações), as empresas de capital aberto brasileiras têm como possibilidade emitir novas ações até um certo limite sem que os acionistas controladores percam o controle, sendo, assim, uma maneira de separar propriedade e controle. Os grandes acionistas parecem utilizar esse mecanismo para manter o controle da companhia sem ter de possuir $50 \%$ do capital total da empresa, alavancando sua posição na mesma. A lei citada até 2001 permitia que as companhias emitissem ações sem direito a voto (ações preferenciais) em uma proporção de até dois terços do total das ações. Dessa maneira, o patamar mínimo para que os acionistas controladores mantivessem o controle da empresa era de $16,3 \%$ do capital total. Essa lei foi revogada após a aprovação da Lei n ${ }^{\circ} 10.303 / 2001$, que mudou a proporção máxima de ações ordinárias e preferenciais de dois terços para $50 \%$, implicando que o controle poderia ser mantido com um mínimo 25,5\% do capital total. Essa mudança é aplicável para novas companhias de capital aberto constituídas a partir de então, bem como para as empresas fechadas que optassem por abrir seu capital. Entretanto, a regra antiga permaneceu válida para empresas de capital aberto constituídas antes da nova Lei.

Nesse contexto legal, Carvalhal-da-Silva e Leal (2006) analisam a estrutura de propriedade e controle de empresas brasileiras e o efeito do fluxo de caixa e dos direitos de voto sobre o valor e desempenho das empresas. A amostra analisada envolveu empresas listadas na Bovespa em 1998, 2000 e 2002. O objetivo principal dos autores foi oferecer uma análise da relação entre a estrutura de governança, o valor da empresa e a performance, entre diferentes grupos de empresas classificadas de acordo com os percentuais de controle resultantes do uso das estruturas de controle direto e indireto.

Como resultados principais, Carvalhal-da-Silva e Leal (2006) constatam que a estrutura de propriedade e controle é bastante concentrada no Brasil, com a maioria das empresas sendo controladas por um único acionista direto. A emissão de ações sem direto a voto parece ser usada por grandes acionistas para manter o controle da empresa sem ter que manter $50 \%$ do capital total. O maior acionista possui na média $77,09 \%$ do capital votante e $55,70 \%$ do capital total em 2002. Entre empresas cujo controle não é detido por um único acionista, o maior deles detém 33\% do capital votante em 2002.

A disparidade da regra uma ação-um voto se torna maior com o uso das estruturas indiretas de controle. Os modelos de regressão de dados em painel apoiam a hipótese de que o valor da firma e o desempenho são relacionados positivamente à concentração do fluxo de caixa, e são negativamente relacionados à concentração de votos e à separação de direito de controle e direito sobre o fluxo de caixa. Empresas cujo principal acionista é um membro familiar são mais comuns no Brasil, e geralmente apresentam maior distância da regra uma ação-um voto e menor valor e desempenho quando comparadas a empresas controladas pelo governo, investidores estrangeiros e institucionais.

Entretanto, observa-se que alguns pontos relevantes evoluíram bastante após o horizonte estudado por Carvalhal-da-Silva e Leal (2006). Em primeiro lugar, a análise até o ano de 2002 seria insuficiente para capturar os efeitos das mudanças promovidas pela Lei $\mathrm{n}^{\circ} 10.303 / 2001$. Em segundo lugar, no período compreendido entre 2004 e 2008 ocorreu um volume significativo de ofertas iniciais e subsequentes de ações (IPOs e follow-ons) na Bovespa ${ }^{1}$. O terceiro e último ponto se refere à implantação efetiva dos níveis de governança corporativa na Bovespa, que se deu a partir de $2002^{2}$. Segundo a BM\&FBovespa (2011), das 110 empresas que abriram capital entre 2004 a 2008, 71\% estavam no Novo Mercado - segmento onde as companhias listadas só podem emitir ações ordinárias com direito a voto, o que mostra uma preocupação recente das empresas em melhorar sua estrutura de governança corporativa.

Os pontos acima apresentados são suficientes para justificar uma revisão do estudo de Carvalhal-da-Silva e Leal (2006) sob uma nova perspectiva, para as empresas brasileiras de capital aberto em período mais recente. Nesse sentido, o presente estudo se baseou principalmente no trabalho desses autores, visando identificar a evolução da estrutura de propriedade e controle das empresas brasileiras e sua relação com o valor/desempenho empresarial para os anos de 2004, 2006 e 2008.

Conforme os autores citados, a estrutura de propriedade e controle sofre pequenas alterações no decorrer do tempo, não justificando uma análise anual. O ano de 2010 e anos posteriores não fizeram parte do horizonte investigado devido ao fato de que a partir do exercício contábil de 2010, as empresas brasileiras de capital aberto passaram a adotar as normas internacionais de contabilidade (IFRS), o que causou variações superiores a $10 \%$ nos lucros, para mais ou para menos, em $35 \%$ dos casos, dentre outras alterações em contas contábeis usadas neste estudo, o que dificultaria as análises comparativas de desempenho e valor (VALOR ECONÔMICO, 2011).

Este artigo é estruturado como segue: a seção 2 apresenta uma breve revisão da literatura sobre estrutura de propriedade e controle e sua relação com desempenho. A seção 3 apresenta a metodologia de pesquisa do estudo. A seção 4 descreve os resultados obtidos e a seção 5 conclui o texto.

1. Em 2002, o número de oferta de ações foi pouco expressivo, ocorrendo apenas 1 IPO e 5 ofertas subsequentes (também chamadas de follow-ons). De 2004 a 2008, ocorreram 110 IPOs e 114 follow-ons, sendo 2007 o ano com maior quantidade de operações de oferta de ações (BM\&F BOVESPA, 2011; CVM, 2011).

2. Pode-se dizer que a implantação efetiva dos níveis de GC na BM\&FBovespa se deu em 2002, ano em que a empresa CCR foi a primeira firma a aderir aos níveis de GC, ingressando no Novo Mercado. 


\section{REFERENCIAL TEÓRICO}

\subsection{Estrutura de propriedade e de controle}

Shleifer e Vishny (1997) afirmam que a estrutura de propriedade e controle e o nível de proteção legal aos investidores variam muito em nível mundial. Apresentam os EUA, a Alemanha, o Reino Unido e o Japão como países que possuem sistemas de governança corporativa (GC) efetivos. Segundo eles, esses quatro países são bem sucedidos em GC devido à sua forma de estrutura de propriedade e proteção legal dos investidores. Por outro lado, países que falham em mecanismos de GC são caracterizados por baixo nível de proteção legal e alta concentração de propriedade. Citam como exemplos desse caso: Itália, países da América Latina, Rússia e Índia.

La Porta et al. (1999) realizaram um estudo sobre a estrutura de propriedade de grandes corporações de 27 países desenvolvidos. Constataram que poucas empresas possuem estrutura dispersa, em contraposição aos estudos de Berle e Means (1932) sobre a propriedade da moderna corporação. Além disso, perceberam que as empresas de sua amostra são controladas por famílias ou pelo Estado. De acordo com eles, existe na literatura financeira uma visão administrativa prevalecente afirmando que a estrutura de propriedade segue o modelo norte-americano de estrutura dispersa entre pequenos acionistas. Nessa ótica, tem-se, por exemplo, os estudos de Jensen e Meckling (1976) e Grossman e Hart (1980). No entanto, conforme o trabalho de La Porta et al. (1999), esse padrão não é tão frequente como se supõe.

Segundo La Porta et al. (1999), estruturas piramidais e a existência de múltiplas classes de ações são duas formas de segregar fluxo de caixa e direito de controle nas empresas e aumentar o efeito entrincheiramento. Concluem que a propriedade sobre o fluxo de caixa pelo acionista majoritário diminui seu incentivo a expropriação. Apontam sugestões e obstáculos para melhorar o ambiente legal e o disclosure corporativo.

Morck et al. (1988) observam uma relação não linear significativa entre propriedade do conselho e valor de mercado da firma, medido pelo $Q$ de Tobin. Os autores apresentam um gráfico em que o $\mathrm{Q}$ de Tobin primeiro aumenta, então diminui, e finalmente aumenta ligeiramente quando o percentual de propriedade do conselho de administração se eleva, caracterizando os conceitos de efeito incentivo e entrincheiramento. Para empresas maduras, constatam que o Q de Tobin é menor quando a firma é administrada por um membro da família fundadora do que quando é gerida por um executivo não relacionado ao fundador.

Corroborando os estudos de La Porta et al. (1999) e Morck et al. (1988), Claessens et al. (2002) estudam de forma conjunta os efeitos incentivo e entrincheiramento. Para tanto, colocam que o ambiente empresarial norteamericano não é adequado para o estudo, pois nos EUA há pouca divergência entre os direitos de fluxo de caixa e os direitos de controle. Assim, decidem trabalhar com uma amostra de 1.301 empresas de capital aberto de oito países da Ásia Oriental. A escolha dos países da Ásia foi justificada pelo fato de as empresas desse continente serem, em geral, controladas por um único acionista e apresentarem grande divergência entre os direitos de controle e de fluxo de caixa.

Como resultado, Claessens et al. (2002) constataram que, por um lado, o valor da firma aumenta com a propriedade do fluxo de caixa do acionista majoritário (efeito incentivo). Por outro lado, o valor da firma se reduz quando os direitos de controle desse acionista superam os direitos sobre o fluxo de caixa (efeito entrincheiramento). Adicionalmente, argumentaram que estruturas piramidais, propriedade cruzada e duplas classes de ações, mesmo não sendo comuns na Ásia Oriental, podem separar os direitos de controle e propriedade e ser associadas com perda de valor da firma. Destacaram, também, que o principal conflito de agência observado na maioria dos países é do tipo majoritáriominoritário, diferente do que ocorre nos EUA.

Pesquisas desenvolvidas por Grossman e Hart (1988) e Harris e Raviv (1988) revelaram que nas empresas de capital aberto em que não funciona o sistema uma açãoum voto, há a tendência de existir maiores benefícios privados de controle, ocorrendo principalmente quando tais empresas se localizam em países com fraca proteção legal.

Outro estudo sobre concentração de propriedade e sistema uma ação-um voto é o de Bozec e Bozec (2007), que investigaram o efeito substituição e o efeito expropriação no mercado de capitais canadense em 2002, para uma amostra de 244 empresas listadas na Bolsa de Toronto. Segundo os autores, de acordo com o efeito substituição, mais poder nas mãos de um acionista controlador leva a um melhor acompanhamento da gestão, diminuindo assim os benefícios de se ter um conselho de administração forte. Por outro lado, de acordo com o efeito expropriação, mais poder nas mãos de um acionista majoritário aumenta o risco de expropriação dos investidores minoritários. Constataram que a concentração de propriedade das empresas canadenses é comum e que as organizações, muitas vezes, se desviam da regra uma ação-um voto, utilizando estruturas piramidais e duplas classes de ações. Seus resultados são consistentes com o efeito expropriação, que prevê um impacto negativo na relação entre a violação da regra uma ação-um voto e melhores práticas de GC. Uma relação negativa e significativa é encontrada entre a separação dos direitos de voto e dos direitos sobre o fluxo de caixa e avaliações de GC. Quando os direitos de voto excedem os direitos sobre o fluxo de caixa, o risco de expropriação é aumentado.

Dando prosseguimento aos estudos de Grossman e Hart (1988) e Harris e Raviv (1988) sobre benefícios privados de controle, Doidge et al. (2005) investigaram tais benefícios e sua relação com a estrutura de propriedade e a decisão de emitir ADRs (cross-listing) em cerca de 4.000 empresas de 31 países da Ásia, Europa e América Latina. Doidge et al. (2005) analisaram os 
direitos de controle (DCONT) e os direitos sobre o fluxo de caixa (DSFC). Segundo eles, se o acionista majoritário detém somente ações ordinárias, ele desejará extrair os benefícios de controle ao máximo. Se ele detém também uma parcela razoável de ações preferenciais sem direito a voto, ao desejar extrair os benefícios de controle, reduzirá o valor da firma no mercado, e passará a reduzir também seu próprio capital. Assim, acionistas majoritários evitam usar os benefícios de controle nessa situação.

Khiari, Karaa e Omri (2007) estudaram a relação entre estrutura de propriedade, papel dos conselhos e desempenho em 320 empresas norte-americanas de capital aberto no período de 1994 a 2001. Constataram um efeito positivo e significativo da eficiência do controle financeiro interno sobre o desempenho. Encontraram também impactos negativos significativos da arbitrariedade administrativa, concentração de propriedade, dominância do conselho pelo CEO e entrincheiramento de gestores sobre o desempenho.

Destefanis e Sena (2007) analisaram a relação entre estrutura de propriedade e eficiência em uma amostra de empresas italianas pertencentes a nove setores de manufatura. Eles verificaram a relação entre indicadores de eficiência das empresas e um conjunto de variáveis explanatórias (variável dummy para ano, dummies territoriais, porcentagem de ações possuídas pelo maior acionista, dummy para grupos piramidais, dummy para definir se o principal acionista é um residente estrangeiro ou uma pessoa física). Constataram que duas características de governança revelam impacto positivo na eficiência: a porcentagem das ações da companhia em poder do maior acionista e o fato de uma empresa pertencer a um grupo com estrutura piramidal.

No contexto brasileiro, Leal, Carvalhal-da-Silva e Valadares (2002) analisaram a estrutura de controle direto e indireto das companhias de capital aberto da Bovespa no ano de 1998. Os resultados apontaram um elevado grau de concentração de capital votante. A amostra envolveu 225 empresas não controladas pelo governo que representavam cerca de $70 \%$ da capitalização de mercado total da Bovespa. No ano de 1998, das 225 empresas, $155(69 \%)$ tinham um único acionista que possuía mais de $50 \%$ do capital votante. Esse acionista possuía em média $74 \%$ do capital votante. Dessa forma, mesmo nos casos em que não há um acionista controlador, o maior acionista detém uma participação significativa dos direitos de voto e a companhia é, geralmente, controlada por seus três maiores acionistas.

Em linha similar, o estudo de Valadares e Leal (2000) verificou que os benefícios privados do controle são expressivos no Brasil e que a utilização de pirâmides como um mecanismo para manutenção de controle não é muito comum no país. Como no Brasil são frequentemente emitidas ações sem direito a voto, a regra uma ação-um voto não é respeitada e os direitos de voto não correspondem aos direitos sobre o fluxo de caixa.

Também no cenário nacional, Silveira (2004) analisou se a estrutura de propriedade e os determinantes da concentração de propriedade influenciam a qualidade da GC. Constatou que quanto maior o poder do acionista controlador em termos de direitos de voto e em termos de desproporcionalidade entre direito de voto e direito sobre o fluxo de caixa, pior a qualidade da GC. Constatou também que, dentre as variáveis de desempenho testadas, o Q de Tobin foi a variável que apresentou relação positiva mais consistente com governança, sugerindo que a adoção de boas práticas de GC tende a ser apreciada pelo mercado. Dando sequência aos estudos de Silveira (2004), Okimura et al. (2004) investigaram a concentrada estrutura de propriedade e controle do Brasil. Os resultados confirmaram as constatações de Silveira (2004), sendo a relação entre estrutura de propriedade/ controle e o valor da firma mais evidente (significativa estatisticamente) do que a relação entre estrutura de propriedade e indicadores de desempenho contábeis.

Outros estudos que analisaram estrutura de propriedade foram: Almeida e Wolfenzon (2006), que investigaram a estrutura piramidal e a estrutura de controle familiar; Barontini e Caprio (2006), que trataram da estrutura de propriedade na Europa continental; Okimura (2003), cujo foco foi a estrutura de propriedade e de controle e sua relação com desempenho e valor de empresas no Brasil; Zolini (2008), que analisou a separação de propriedade e controle e valor das empresas brasileiras.

\section{METODOLOGIA}

A amostra deste estudo é proveniente de empresas brasileiras de capital aberto listadas na BM\&FBovespa, nos anos de 2004, 2006 e 2008. Para selecionar a amostra de análise, utilizou-se um filtro de liquidez sugerido por Silveira (2004). Consideraram-se como empresas com liquidez significativa aquelas que apresentaram índice de liquidez anual maior que $0,001 \%$ do índice correspondente à empresa com ações mais líquidas em quatro anos ou mais do período de 2000 a 2009, incluindo necessariamente o ano de 2009. O setor de Finanças e Seguros foi excluído da amostra devido às suas diferenças estruturais. A amostra final ficou composta de 246 empresas após os filtros de liquidez, dados e setor financeiro.

Os dados sobre desempenho e valor foram retirados da base Economática e os dados sobre estrutura de propriedade e controle foram obtidos na CVM (Comissão de Valores Mobiliários) através do formulário de informações anuais (IAN) das companhias estudadas. O IAN apresenta as principais informações financeiras e não financeiras das empresas, e dentre as informações disponíveis está a composição do capital social das empresas. A partir de 2009, com as Instruções CVM $\mathrm{n}^{\circ} 480$ e $481^{3}$, o IAN foi substituído pelo formulário de referência. A amostra selecionada é fixa para os

3. Instrução CVM n 480 , de 7 de dezembro de 2009 e Instrução CVM n ${ }^{\circ} 481$ de 17 de dezembro de 2009, obtidas no site www. cvm.gov.br. 
anos analisados. Dessa maneira, se uma empresa abriu seu capital a partir de 2006, por exemplo, será utilizada a informação societária de 2006 e 2008. Foi possível identificar, através do IAN, os acionistas com participação de no mínimo $5 \%$ do capital votante das empresas analisadas.

O presente estudo se baseou apenas na participação direta dos acionistas nas empresas analisadas. Além disso, foi feita uma diferenciação entre empresas com controle definido e empresas de capital pulverizado, as quais apresentam mais de $50 \%$ do capital votante sob a forma de free float.

Não foi considerada a possível existência de blocos de controle. Isso porque a informação que se tem disponível no IAN é sobre a existência (ou não) de acordo de acionistas entre os sócios, porém, entendese que a existência de um acordo de acionistas não necessariamente pressupõe a existência de um bloco de controle.

Para verificar a relação entre estrutura de propriedade das organizações e valor/desempenho foi usada a Análise de Dados em Painel. Tal análise é usada quando se trabalha com dados longitudinais, em que um corte transversal de empresas é observado com o tempo. As vantagens de se usar esse tipo de modelo consistem na possibilidade de se lidar com a heterogeneidade das unidades e na redução dos problemas de multicolinearidade. Há alguns métodos que permitem tratar a heterogeneidade dos dados, quais sejam: o modelo de efeitos fixos e o modelo de efeitos aleatórios (STOCK; WATSON, 2004). Visando decidir entre o melhor modelo, usou-se o Teste de Hausman, no software Stata/SE 11.0.

As variáveis dependentes alternadas nos modelos foram: Q de Tobin, Retorno sobre o Ativo (ROA) e Price to Book Ratio. As variáveis explicativas dos modelos foram: percentual de capital votante do maior, dos 3 maiores e dos 5 maiores acionistas; percentual de capital total do maior, dos 3 maiores e dos 5 maiores acionistas; razão capital votante sobre capital total para as mesmas classes de acionistas; e variáveis para identidade do controlador. Por fim, as variáveis de controle foram tamanho da empresa, volatilidade e crescimento da receita nos últimos três anos.

\section{RESULTADOS EMPÍRICOS}

\subsection{Análise da composição acionária direta}

Buscou-se identificar para cada companhia o maior, os três maiores e os cinco maiores acionistas tanto para o capital votante (ações ordinárias) como para o capital total (ações ordinárias somadas às ações preferenciais).

Em seguida, foi calculada a relação entre a participação dos acionistas nas ações ordinárias sobre a participação total. Esse índice permite analisar a alavancagem média de posição dos acionistas controladores nas empresas brasileiras ${ }^{4}$. Os resultados encontrados são apresentados na Tabela 1.

Observa-se que nas empresas onde há controle acionário definido, a participação média do maior acionista é bastante concentrada (acima de $50 \%$ do capital votante), representando $59,9 \%, 55,5 \%$ e $56,2 \%$ em 2004 , 2006 e 2008 respectivamente. Entretanto, a quantidade de empresas com essa característica vem reduzindo ao longo do tempo, uma vez que estas representam $69 \%$ (124 de 181 empresas) em 2004, 59\% (127 de 215 empresas) em 2006 e $62 \%$ (138 em 224 empresas) em 2008. O número de empresas da amostra aumenta de 2004 para 2008 em função de novas aberturas de capital. Esses resultados sugerem que essas novas empresas apresentam concentração de capital menos acentuada do que as empresas existentes em 2004.

A concentração de capital é acentuada mesmo para as empresas de capital pulverizado, uma vez que a participação do maior acionista controlador é ainda considerável, passando de $17,8 \%$ em 2004 para 20,2\% em 2008

Em 2008, a participação média dos três maiores acionistas no capital votante de empresas com controle definido representa $75,9 \%$ e a participação dos cinco maiores acionistas é de $80,4 \%$. Ou seja, no Brasil existe uma grande concentração do controle em poder de poucos acionistas. Mesmo para a amostra total, os percentuais registrados em 2008 foram de $72,4 \%$ para os três maiores acionistas e de $76,9 \%$ para os cinco maiores acionistas, o que ainda aponta para uma alta concentração do capital votante.

É interessante ressaltar que a razão capital votante sobre capital total vem diminuindo ao longo do tempo. Em 2004 para a amostra total, esse índice era de 1,45 para o maior acionista controlador, sendo reduzido para $1,33 \mathrm{em} 2006$ e para $1,28 \mathrm{em} 2008$.

Esse efeito pode ser explicado tanto pelas consequências da restrição imposta pela Lei $\mathrm{n}^{\circ}$ 10.303/2001 como também pela quantidade de empresas estreantes na bolsa que optaram pelo Novo Mercado, que impõe a existência apenas de ações ordinárias na composição do capital das empresas.

No caso das empresas de capital pulverizado, a relação é bastante próxima de 1 em 2004 e passa a ser igual a 1 a partir de 2006, indicando que o capital de empresas de controle disperso é composto totalmente por ações ordinárias.

\footnotetext{
4. Empresas de capital aberto que apresentam ações ordinárias e preferenciais e que foram constituídas antes da Lei ${ }^{\circ} 10.303 / 2001$ podem ter uma razão de participação nas ordinárias em relação à participação total máxima de 3 vezes $(50 \%$ ONs em relação a $16,7 \%$ de capital total). Raciocínio análogo pode ser aplicado a empresas que foram constituídas após a lei, chegando-se a uma razão máxima de 2 vezes ( $50 \%$ ONs em relação a $25 \%$ do capital total).
} 
Tabela 1. Composição acionária direta de empresas brasileiras

\section{A: 2004}

\begin{tabular}{|c|c|c|c|c|c|c|c|c|c|}
\hline & \multicolumn{3}{|c|}{$\begin{array}{c}\text { Empresas com controle definido (181 } \\
\text { empresas) }\end{array}$} & \multicolumn{3}{|c|}{$\begin{array}{c}\text { Empresas de capital pulverizado (3 } \\
\text { empresas) }\end{array}$} & \multicolumn{3}{|c|}{$\begin{array}{c}\text { Amostra total } \\
\text { (184 empresas) }\end{array}$} \\
\hline & $\begin{array}{c}\text { Capital } \\
\text { votante } \\
(\%)\end{array}$ & $\begin{array}{l}\text { Capital } \\
\text { total }(\%)\end{array}$ & $\begin{array}{c}\text { Capital } \\
\text { votante/ } \\
\text { total }\end{array}$ & $\begin{array}{c}\text { Capital } \\
\text { votante } \\
(\%)\end{array}$ & $\begin{array}{c}\text { Capital } \\
\text { total } \\
(\%)\end{array}$ & $\begin{array}{c}\text { Capital } \\
\text { votante/ } \\
\text { total }\end{array}$ & $\begin{array}{c}\text { Capital } \\
\text { votante } \\
(\%)\end{array}$ & $\begin{array}{c}\text { Capital } \\
\text { total } \\
(\%)\end{array}$ & $\begin{array}{c}\text { Capital } \\
\text { votante } \\
\text { total }\end{array}$ \\
\hline $\begin{array}{l}\text { Maior } \\
\text { acionista }\end{array}$ & 59.87 & 41.38 & 1.45 & 17.78 & 18.10 & 0.98 & 59.18 & 41.00 & 1.44 \\
\hline $\begin{array}{l}3 \text { maiores } \\
\text { acionistas }\end{array}$ & 80.77 & 59.20 & 1.36 & 26.42 & 26.78 & 0.99 & 79.89 & 58.67 & 1.36 \\
\hline $\begin{array}{l}5 \text { maiores } \\
\text { acionistas }\end{array}$ & 84.91 & 62.81 & 1.35 & 29.45 & 29.83 & 0.99 & 84.00 & 62.28 & 1.35 \\
\hline
\end{tabular}

\section{B: 2006}

\begin{tabular}{|c|c|c|c|c|c|c|c|c|c|}
\hline & \multicolumn{3}{|c|}{$\begin{array}{c}\text { Empresas com controle definido (215 } \\
\text { empresas) }\end{array}$} & \multicolumn{3}{|c|}{$\begin{array}{c}\text { Empresas de capital pulverizado (20 } \\
\text { empresas) }\end{array}$} & \multicolumn{3}{|c|}{$\begin{array}{c}\text { Amostra total } \\
\text { (235 empresas) }\end{array}$} \\
\hline & $\begin{array}{c}\text { Capital } \\
\text { votante } \\
(\%)\end{array}$ & $\begin{array}{l}\text { Capital } \\
\text { total }(\%)\end{array}$ & $\begin{array}{c}\text { Capital } \\
\text { votante/ } \\
\text { total }\end{array}$ & $\begin{array}{c}\text { Capital } \\
\text { votante } \\
(\%)\end{array}$ & $\begin{array}{c}\text { Capital } \\
\text { total } \\
(\%)\end{array}$ & $\begin{array}{c}\text { Capital } \\
\text { votante/ } \\
\text { total }\end{array}$ & $\begin{array}{c}\text { Capital } \\
\text { votante } \\
(\%)\end{array}$ & $\begin{array}{c}\text { Capital } \\
\text { total } \\
(\%)\end{array}$ & $\begin{array}{c}\text { Capital } \\
\text { votante } \\
\text { total }\end{array}$ \\
\hline $\begin{array}{c}\text { Maior } \\
\text { acionista }\end{array}$ & 55.54 & 41.13 & 1.35 & 21.30 & 21.30 & 1.00 & 52.63 & 39.44 & 1.33 \\
\hline $\begin{array}{l}3 \text { maiores } \\
\text { acionistas }\end{array}$ & 75.88 & 61.13 & 1.24 & 33.96 & 33.96 & 1.00 & 72.31 & 58.82 & 1.23 \\
\hline $\begin{array}{l}5 \text { maiores } \\
\text { acionistas }\end{array}$ & 80.53 & 66.79 & 1.21 & 38.68 & 38.68 & 1.00 & 76.96 & 64.39 & 1.20 \\
\hline
\end{tabular}

C: 2008

\begin{tabular}{|c|c|c|c|c|c|c|c|c|c|}
\hline & \multicolumn{3}{|c|}{$\begin{array}{l}\text { Empresas com controle definido } \\
\text { (224 empresas) }\end{array}$} & \multicolumn{3}{|c|}{$\begin{array}{c}\text { Empresas de capital pulverizado (22 } \\
\text { empresas) }\end{array}$} & \multicolumn{3}{|c|}{$\begin{array}{c}\text { Amostra total } \\
\text { (246 empresas) }\end{array}$} \\
\hline & $\begin{array}{c}\text { Capital } \\
\text { votante } \\
(\%)\end{array}$ & $\begin{array}{l}\text { Capital } \\
\text { total }(\%)\end{array}$ & $\begin{array}{c}\text { Capital } \\
\text { votante/ } \\
\text { total }\end{array}$ & $\begin{array}{c}\text { Capital } \\
\text { votante } \\
(\%)\end{array}$ & $\begin{array}{c}\text { Capital } \\
\text { total } \\
(\%)\end{array}$ & $\begin{array}{l}\text { Capital } \\
\text { votante/ } \\
\text { total }\end{array}$ & $\begin{array}{c}\text { Capital } \\
\text { votante } \\
(\%)\end{array}$ & $\begin{array}{c}\text { Capital } \\
\text { total } \\
(\%)\end{array}$ & $\begin{array}{c}\text { Capital } \\
\text { votante/ } \\
\text { total }\end{array}$ \\
\hline $\begin{array}{l}\text { Maior } \\
\text { acionista }\end{array}$ & 56.25 & 43.39 & 1.30 & 20.16 & 20.16 & 1.00 & 53.03 & 41.31 & 1.28 \\
\hline $\begin{array}{l}3 \text { maiores } \\
\text { acionistas }\end{array}$ & 75.88 & 63.26 & 1.20 & 36.22 & 36.22 & 1.00 & 72.34 & 60.84 & 1.19 \\
\hline $\begin{array}{l}5 \text { maiores } \\
\text { acionistas }\end{array}$ & 80.37 & 68.79 & 1.17 & 41.20 & 41.20 & 1.00 & 76.87 & 66.33 & 1.16 \\
\hline
\end{tabular}

Fonte: Resultados da pesquisa.

A amostra foi classificada de acordo com a identidade do maior acionista controlador. Buscouse com isso distinguir a estrutura de propriedade nas seguintes classes: a)empresas de origem familiar; b) investidores institucionais; c) estrangeiros; d) empresas privadas nacionais cujo controlador não seja família ou investidores institucionais (p. ex: holdings acionistas de várias empresas); e) empresas de controle federal, estatal e/ou municipal; e f) empresas cujo maior acionista não é o controlador, dado que a empresa é de capital pulverizado. O quadro 1 mostra a classificação de acordo com o tipo de controlador e as tabelas 2 e 3 apresentam os resultados encontrados.

A tabela 2 sugere que composição acionária das empresas brasileiras vem mudando bastante ao longo do tempo, uma vez que os acionistas de empresas familiares, de capital privado e estatais vêm perdendo espaço para dar lugar à acionistas institucionais, estrangeiros e acionistas pulverizados. Isso pode ser consequência do volume expressivo de abertura de capital que ocorreu no período analisado.

Quanto à participação ordinária de cada tipo de acionista, a tabela 3 aponta que, dentre os tipos de acionistas majoritários da amostra, existe maior concentração de capital votante em empresas de controle estatal $(62,8 \%, 67,1 \%$ e $68,0 \%$ em 2004, 2006, 2008 respectivamente), seguidos de empresas de origem familiar $(61,2 \%, 54,4 \%$ e $55,4 \%)$, e de capital privado $(56,6 \%, 57,5 \%$ e $61,3 \%)$. A evolução das participações inclusive sugere um aumento de concentração acionária em empresas estatais e privadas e uma redução de concentração acionária em empresas de origem familiar. 


\begin{tabular}{|c|l|}
\hline Classificação & \multicolumn{1}{c|}{ Tipo de acionista } \\
\hline 1 & Indivíduos ou Famílias, ou holdings/fundações que representam a família. \\
\hline 2 & $\begin{array}{l}\text { Investidores Institucionais (bancos, companhias de seguro, fundos de pensão, fundos de investimento, fundações ou } \\
\text { fundos mútuos). }\end{array}$ \\
\hline 3 & Estrangeiros (indivíduos ou empresas). \\
\hline 4 & Empresas privadas nacionais (não sendo provenientes da família fundadora da empresa e não sendo investidor institucional). \\
\hline 5 & Governo (União, Estados ou Municípios). \\
\hline 6 & Maior acionista ordinário não é o controlador (empresa de capital pulverizado). \\
\hline
\end{tabular}

Quadro 1. Classificação do maior acionista controlador por tipo

Fonte: elaborado pelos autores.

Tabela 2. Composição da amostra por tipo de acionista controlador

\begin{tabular}{|c|c|c|c|c|}
\hline & Tipo de acionista (\%) & 2004 & 2006 & 2008 \\
\hline 1 & Indivíduos ou Famílias & 59.78 & 57.45 & 52.85 \\
\hline 2 & Investidores Institucionais & 3.80 & 3.83 & 6.50 \\
\hline 3 & Estrangeiros & 8.15 & 12.77 & 10.57 \\
\hline 4 & Empresas privadas nacionais & 19.02 & 15.74 & 17.89 \\
\hline 5 & Governo & 8.15 & 5.96 & 5.69 \\
\hline 6 & Maior acionista ordinário não é o controlador & 1.09 & 4.26 & 6.50 \\
\hline
\end{tabular}

Fonte: Resultados da pesquisa.

Tabela 3. Estrutura de propriedade de empresas brasileiras por tipo de acionista

\begin{tabular}{|c|c|c|c|c|c|c|c|c|c|}
\hline \multirow[b]{2}{*}{$\begin{array}{c}\text { Tipo de } \\
\text { acionista }\end{array}$} & \multicolumn{3}{|c|}{2004} & \multicolumn{3}{|c|}{2006} & \multicolumn{3}{|c|}{2008} \\
\hline & $\begin{array}{l}\text { Capital } \\
\text { votante }\end{array}$ & $\begin{array}{c}\text { Capital } \\
\text { total }\end{array}$ & $\begin{array}{l}\text { Capital } \\
\text { votante/ } \\
\text { total }\end{array}$ & $\begin{array}{l}\text { Capital } \\
\text { votante }\end{array}$ & $\begin{array}{c}\text { Capital } \\
\text { total }\end{array}$ & $\begin{array}{c}\text { Capital } \\
\text { votante/ } \\
\text { total }\end{array}$ & $\begin{array}{l}\text { Capital } \\
\text { votante }\end{array}$ & $\begin{array}{c}\text { Capital } \\
\text { total }\end{array}$ & $\begin{array}{c}\text { Capital } \\
\text { votante/ } \\
\text { total }\end{array}$ \\
\hline Famílias & 61.16 & 38.13 & 1.60 & 54.43 & 37.59 & 1.45 & 55.43 & 38.79 & 1.43 \\
\hline Institucionais & 51.15 & 47.49 & 1.08 & 31.23 & 30.72 & 1.02 & 30.60 & 27.95 & 1.09 \\
\hline Estrangeiros & 56.03 & 46.24 & 1.21 & 50.75 & 43.26 & 1.17 & 54.15 & 48.37 & 1.12 \\
\hline Privados & 56.60 & 40.65 & 1.39 & 57.51 & 43.40 & 1.33 & 61.27 & 49.96 & 1.23 \\
\hline Governo & 62.79 & 46.14 & 1.36 & 67.07 & 46.23 & 1.45 & 68.01 & 48.01 & 1.42 \\
\hline Sem controlador & 8.42 & 8.05 & 1.05 & 14.92 & 14.92 & 1.00 & 18.28 & 18.28 & 1.00 \\
\hline
\end{tabular}

Fonte: Resultados da pesquisa.

A relação entre a participação no capital votante sobre capital total do acionista majoritário é mais acentuada nas empresas de origem familiar, capital privado, seguidas das firmas de controle estatal, indicando que esses tipos de acionistas são os que mais utilizam esse recurso como forma de separação entre controle e propriedade.

Entretanto, percebe-se uma tendência de redução desse índice quando se compara os dados de $2008 \mathrm{em}$ relação a 2004, para as empresas familiares (-11\%) e para investidores privados (-12\%); e uma tendência de aumento do índice $(+4 \%)$ em firmas cujo acionista majoritário é o Estado.

\subsection{Relação entre estrutura de propriedade e performance}

Foram feitas regressões em painel para avaliar a relação entre valor (medido através do $\mathrm{Q}$ de Tobin e do índice Price to Book Ratio) e performance medida pelo Retorno sobre o Ativo (ROA) com a estrutura de propriedade das em empresas brasileiras de capital aberto.

O Q de Tobin foi calculado de acordo com a aproximação de Chung e Pruitt (1994), onde o mesmo é obtido através da relação:

$Q$ de Tobin = ((Valor de mercado+Passivo Circulante+Exigivel a Longo Prazo+Estoques-Ativo Circulante)) / (Ativo Total)

Como variáveis de controle foram utilizadas: (i) a volatilidade, medida através do desvio padrão dos retornos das ações nos últimos 12 meses; (ii) o tamanho da empresa, medido através do logaritmo natural do Ativo 
Total; (iii) o crescimento médio das vendas, medido pelo crescimento da receita operacional líquida nos últimos três anos.

A estrutura de propriedade no modelo foi especificada através da participação ordinária e total do maior acionista da empresa e do índice participação no capital votante sobre participação no capital total. Para a análise da estrutura de propriedade por tipo de acionista controlador, foram inseridas variáveis dummy que representassem cada classificação, sendo considerada 1 se for do tipo de acionista em questão e 0 para os demais.

As especificações finais do modelo são apresentadas nas equações (1), (2) e (3) a seguir:

$Q d e$ Tobin $=\beta \_0+\beta \_1 O N+\beta \_2$ Total $+\beta \_3$ ON/Total $+\beta \_4$ familiar $+\beta \_5$ institucional $+\beta \_6 \quad$ estrangeiros $+\beta \_7$ privados $+\bar{\beta} 8 \quad$ estatal $+\beta \_9$ semcontrol $+\beta{ }_{-} \overline{1} 0$ volatilidade $+\beta \_11$ tamanho $+\beta \_12$ cresc $+\varepsilon$ (1)

$P / B=\beta \_0+\beta \_1$ ON $+\beta \_2$ Total $+\beta \_3 \quad$ ON/Total $+\beta \_4$ familiar $+\beta \_5$ institucional $+\beta \_6$ estrangeiros $+\beta \_7$ privados $+\beta \quad 8 \quad$ estatal $+\beta 9 \quad$ semcontrol $+\beta \quad 10$ volatilidade $+\beta \_11$ tamanho $+\beta \_12$ cresc $+\varepsilon$ (2)

$R O A=\beta 0+\beta 1 O N+\beta 2$ Total $+\beta 3 \quad$ ON $/$ Total $+\beta 4$ familiar $+\beta \_5$ institucional $+\beta \_6$ estrangeiros $+\beta \_7$ privados $+\bar{\beta} 8$ estatal $+\beta \_9$ semcontrol $+\beta \_\overline{10}$ volatilidade $+\beta \_11$ tamanho $+\beta \_12$ cresc $+\varepsilon$ (3)

Onde:

Destaca-se que para cada variável dependente $(\mathrm{Q}$ de Tobin, $\mathrm{P} / \mathrm{B}$ e ROA) houve o desdobramento em três modelos estimados, contendo respectivamente: $\left(1^{\circ}\right)$ variáveis de estrutura de propriedade/controle considerando o maior acionista; $\left(2^{\circ}\right)$ variáveis que consideram os três maiores acionistas; e (c) as que levam em consideração os cinco maiores acionistas.

Os testes de Hausman, para todas as variáveis dependentes e especificações, apontaram que os efeitos individuais nos modelos são importantes e que o modelo mais adequado a ser utilizado é o modelo de efeitos fixos.

Tabela 4. Associações entre Estrutura de Propriedade/Controle e Valor/Desempenho

\begin{tabular}{|c|c|c|c|c|c|c|c|c|c|}
\hline \multirow{2}{*}{ Variáveis } & \multicolumn{3}{|c|}{ Q de Tobin } & \multicolumn{3}{|c|}{ ROA } & \multicolumn{3}{|c|}{ Price/Book } \\
\hline & I & II & III & IV & $\mathbf{V}$ & VI & VII & VIII & IX \\
\hline on_maior & $-0,0000$ & & & $-0,4634^{*}$ & & & $-0,0602 *$ & & \\
\hline total_maior & $-0,0072$ & & & 0,1787 & & & 0,0521 & & \\
\hline ontotal_maior & $-1,1756^{*}$ & & & 11,5644 & & & 1,4923 & & \\
\hline cont1 & $-1,0674$ & $-1,1247$ & $-1,2894$ & $-21,4662 *$ & $-18,6050^{*}$ & $-18,6458^{*}$ & 19,8678 & 20,0064 & 19,8449 \\
\hline cont 2 & $1,6145^{*}$ & $1,4542 *$ & 1,5692 & 17,8196 & 19,5532 & 20,4694 & $14,1159^{*}$ & $14,5543^{*}$ & $14,5009^{*}$ \\
\hline cont 3 & $-1,2143$ & $-1,3125$ & $-1,4803$ & $38,2842^{*}$ & $37,3671^{*}$ & $37,6228^{*}$ & $19,1256^{*}$ & $19,1938^{*}$ & $19,2146^{*}$ \\
\hline cont4 & $-1,2797$ & $-1,3137$ & $-1,5037$ & 28,4239 & 24,9693 & 25,1351 & 18,5301 & 18,5156 & 18,4867 \\
\hline cont5 & $-2,7065$ & $-2,0894$ & $-2,1400$ & 22,9422 & 24,0479 & 24,2707 & $-17,1398 *$ & $-16,9858$ & $-17,4923^{*}$ \\
\hline \multicolumn{10}{|l|}{ cont6 } \\
\hline Volatilidade & 62,9945 & 57,0460 & 55,7923 & $-104,1375$ & $-92,1500$ & $-91,2655$ & 0,6321 & 1,5761 & 2,0238 \\
\hline Tamanho & $-5,8166$ & $-5,9105$ & $-5,9518$ & $44,0850^{*}$ & $45,9691 *$ & $46,2031^{*}$ & 1,9518 & 2,0696 & 2,1222 \\
\hline Crescimento & $-0,0881$ & $-0,0836$ & $-0,0824$ & 4,1423 & 5,4028 & 5,4200 & 0,0422 & 0,0531 & 0,0472 \\
\hline on_3maiores & & 0,0176 & & & $-0,2904$ & & & $-0,1121^{*}$ & \\
\hline total_3maiores & & $-0,0264$ & & & 0,2803 & & & $0,1114^{*}$ & \\
\hline ontotal_3maiores & & $-2,0002 *$ & & & 18,5608 & & & $-3,1788^{*}$ & \\
\hline on_5maiores & & & 0,0313 & & & $-0,2974$ & & & $-0,0423$ \\
\hline total_5maiores & & & $-0,0304$ & & & 0,2992 & & & 0,0385 \\
\hline ontotal_5maiores & & & $-2,1627$ & & & 19,2540 & & & 1,6936 \\
\hline $\mathrm{N}$ & 461 & 461 & 461 & 457 & 457 & 457 & 461 & 461 & 461 \\
\hline L1 & $-1213,79$ & $-1213,14$ & $-1212,95$ & $-2182,69$ & $-2.183,38$ & $-2.183,38$ & $-1197,97$ & $-1196,67$ & $-1198,32$ \\
\hline $\begin{array}{l}\text { Teste de Hausman } \\
\text { (valor } p)\end{array}$ & 0,0002 & 0,0003 & 0,0003 & 0,0029 & 0,0022 & 0,0023 & 0,0367 & 0,0023 & 0,0008 \\
\hline
\end{tabular}

Fonte: Resultados da pesquisa. 
Notas: os asteriscos indicam os níveis de significância: $* \mathrm{p}<0,05 ; * * \mathrm{p}<0,01 ; * * * \mathrm{p}<0,001$. As variáveis dependentes em cada regressão são Q de Tobin, Retorno sobre o Ativo (ROA) e razão Price to Book (P/B). Todos os coeficientes foram obtidos por meio de modelos em painel com efeitos fixos. As definições para cada uma das variáveis podem ser encontradas no Apêndice, Tabela A. Os dados incluem empresas brasileiras de capital aberto nos anos de 2004, 2006 e 2008.

No modelo com $Q$ de Tobin, as variáveis que apresentaram significância estatística ao nível de 5\% foram: ontotal_maior (razão capital votante sobre capital total do maior acionista), com sinal negativo; ontotal_3maiores (mesma razão para os 3 maiores acionistas), com sinal negativo e cont2 (controlador é investidor institucional), com sinal positivo, nas duas primeiras especificações (I e II). Isso indica, conforme esperado, que quanto mais concentrada é a estrutura de propriedade e controle no maior e nos 3 maiores acionistas, menor será o valor de mercado medido pelo $\mathrm{Q}$ de Tobin. E também que o fato de o acionista controlador ser investidor institucional eleva o valor da empresa (TAB. 4).

No modelo cuja variável dependente é o ROA, as variáveis significativas e positivas foram: cont3 (controlador é estrangeiro) e tamanho da firma, indicando que empresas maiores e controladas por companhias estrangeiras apresentam maior rentabilidade. Por sua vez, as variáveis significativas e negativas foram: on_maior (percentual de capital votante do maior acionista) e cont1 (controlador é uma família), isto é, empresas familiares e cujo acionista majoritário detém elevado percentual de capital com direito a voto tendem a apresentar menor rentabilidade para a amostra analisada (TAB. 4).

No que se refere ao modelo cuja variável resposta é Price/Book, as variáveis significativas e positivas foram: cont2 (controlador é investidor institucional), cont3 (controlador é estrangeiro) e total_3 maiores (percentual de capital total dos 3 maiores acionistas). Já as variáveis significativas e negativas foram: on_maior (percentual do capital votante do maior acionista), cont5 (controlador é um ente do governo), on 3maiores (percentual do capital votante dos 3 maiores acionistas) e ontotal_3maiores (razão capital votante capital total dos 3 maiores acionistas).

Logo, pode-se inferir que empresas controladas por investidores institucionais ou por companhias estrangeiras apresentam maior valor, medido pela razão Price/Book. Além disso, empresas com controlador governamental e estrutura de propriedade/controle concentrada nas mãos dos maiores acionistas apresentam menor Price/Book, o que era esperado na literatura de finanças (TAB. 4).

Em geral, pode-se dizer que as duas hipóteses deste estudo foram comprovadas: (a) há relação inversa entre o direito de controle detido pelo acionista controlador (on maior, ontotal_maior, on_3maiores, ontotal_3maiores) e a melhoria no valor empresarial; e (b) há relação positiva entre o direito sobre o fluxo de caixa detido pelo acionista controlador (total_maior, total_3maiores) e a melhoria no valor da firma medido por Price/Book.

\section{CONSIDERAÇÕES FINAIS}

O presente estudo analisou a situação da estrutura de propriedade e controle das empresas brasileiras de capital aberto listadas na Bovespa nos anos de 2004, 2006 e 2008. Buscou também verificar a existência de uma relação entre a concentração de capital votante e de capital total com desempenho e valor das empresas. No que tange ao método, foi adotada a Análise de Dados em Painel, utilizando a modelagem de efeitos fixos.

Como resultado, constatou-se que no Brasil ainda existe grande concentração de controle em poder de poucos acionistas. Entretanto, o estudo revelou uma tendência de redução dessa concentração ao longo do período analisado. Nas empresas com controle definido, há concentração de direito de voto em poder do acionista majoritário, representando respectivamente 59,9\%, $55,5 \%$ e 56,2\% em 2004, 2006 e 2008.

Em 2008, desconsiderando as empresas de capital pulverizado, a participação dos três maiores acionistas no capital com direito de voto foi de $75,9 \%$, e dos cinco maiores $80,4 \%$. A razão capital votante sobre capital total vem se reduzindo, o que é positivo para a governança corporativa.

Considerando a amostra total, em 2004 esse índice era de 1,45 para o maior acionista controlador, sendo reduzido para 1,33 em 2006 e para 1,28 em 2008. Podese inferir que isso tem ocorrido em função das restrições impostas pela Lei $\mathrm{n}^{\circ} 10.303 / 2001$ e também pela quantidade de empresas estreantes na bolsa que optaram pelo Novo Mercado, onde só existem ações ordinárias.

Quanto à identidade do controlador, os acionistas de empresas familiares, de empresas de capital privado e estatais vêm perdendo espaço para dar lugar aos acionistas institucionais, estrangeiros e acionistas pulverizados. Há maior concentração de capital votante em empresas de controle estatal, seguidos de empresas de origem familiar e de capital privado. No período de 2004 a 2008, a alavancagem da posição acionária (relação capital votante por capital total) tem se reduzido para as empresas familiares $(-11 \%)$ e para investidores privados $(-12 \%)$ e tem aumentado para as empresas estatais $(+4 \%)$.

No que tange à relação entre estrutura de propriedade e valor/performance, constatou-se que a concentração de propriedade/controle, ainda presente nas firmas brasileiras, tem um efeito negativo sobre o valor e o desempenho (rentabilidade) das empresas, comprovando os estudos de Claessens et al. (2002) e Bozec e Bozec (2007), por exemplo. Além disso, infere-se que o fato de a firma possuir um controlador estrangeiro ou institucional eleva o valor e a performance empresarial. E que, para a amostra e período analisados, firmas controladas pela 
família ou pelo governo podem ter reduções em sua rentabilidade e valor, respectivamente.

\section{REFERÊNCIAS}

ALMEIDA, H. V.; WOLFENZON, D. A Theory of Pyramidal Ownership and Family Business Groups. The Journal of Finance. v. 61, n. 6, p. 2637-2680, 2006.

BARONTINI, R.; CAPRIO, L. The Effect of Family Control on Firm Value and Performance: Evidence from Continental Europe. European Financial Management, v. 12, n. 5, p. 689-723, 2006.

BERLE, A. A.; MEANS, G. C. The modern corporation and private property. New York: MacMillan, 1932.

BM\&FBOVESPA. Estatísticas das Aberturas de Capital na BM\&FBOVESPA. Disponível em: $\quad<$ http://www.bmfbovespa.com.br/ciaslistadas/consultas/ipos-recentes/ipos-recentes. aspx?idioma=pt-br>. Acesso em: 20 jun. 2011.

BORTOLON, P. M. Por que as empresas brasileiras adotam estruturas piramidais de controle. BASE - Revista de Administração e Contabilidade da UNISINOS, v. 10, n. 1, p. 2-18, 2013.

BOZEC, Y.; BOZEC, R. Ownership Concentration and Corporate Governance Practices: Substitution or Expropriation Effects? Canadian Journal of Administrative Sciences (CJAS). v. 24, n. 3, p. 182-195, 2007.

CAIXE, D. F.; KRAUTER, E. A influência da estrutura de propriedade e controle sobre o valor de mercado corporativo no Brasil. Revista Contabilidade \& Finanças - USP, v. 24, n. 62, p. 142-153, 2013.

CARVALHAL-DA-SILVA, A. L.; LEAL, R. P. C. Corporate Governance Index, firm valuation and performance in Brazil. Revista Brasileira de Finanças. v. 3, n. 1, p. 1-18, 2005.

CARVALHAL-DA-SILVA, A. L.; LEAL, R. P. C. Ownership, control, valuation and performance of brazilian corporations. Corporate Ownership \& Control. v. 4, n. 1, p. 300-308, 2006.

CHUNG, K.; PRUITT, S. A simple approximation of Tobin's Q. Financial Management. v. 23, n. 3, p. 70-74, 1994.

CLAESSENS, S.; DJANKOV, S.; FAN, J. P. H.; LANG, L. H. P. Disentangling the Incentive and Entrenchment Effects of Large Shareholdings. The Journal of Finance. v. 57, n. 6, p. 2741-2771, 2002.

COMISSÃO DE VALORES MOBILIÁRIOS. Instrução
CVM no 480, de 7 dezembro de 2009 (a). Disponível em: < http://www.cvm.gov.br/>. Acesso em: 20 jun. 2011.

COMISSÃO DE VALORES MOBILIÁRIOS. Instrução CVM no 481, de 17 dezembro de 2009 (b). Disponível em: < http://www.cvm.gov.br/>. Acesso em: 20 jun. 2011.

DESTEFANIS, S.; SENA, V. Patterns of Corporate Governance and Technical Efficiency in Italian Manufacturing. Managerial and Decision Economics. v. 28, p. 27-40, 2007.

DOIDGE, C.; KAROLYI, G. A.; STULZ, R. M.; LINS, K. V.; MILLER, D. P. Private benefits of control, ownership, and the cross-listing decision. ECGI - Finance Working Paper n. 77, Dice Center Working Paper n. 2. 2005. Disponível em: $<\mathrm{http}: / /$ ssrn.com/abstract $=668424>$. Accessed in: 7 may 2010 .

GROSSMAN, S.; HART, O. One-share-one-vote and the market for corporate control. Journal of Financial Economics. v. 20, p. 175-202, 1988.

GROSSMAN, S.; HART, O. Takeover bids, the freerider problem and the theory of the corporation. Bell Journal of Economics. v.11, p. 42-64, 1980.

HARRIS, M.; RAVIV, A. Corporate governance: Voting rights and majority rules. Journal of Financial Economics. v. 20, p. 203-236, 1988.

HOFFMANN, R.; BORTOLUZZO, A. B.; MACHADO, S. J. Impacto da estrutura de propriedade e do nível de governança corporativa no ajuste parcial de preços em um IPO. Revista de Economia e Administração, v. 12, n. 1, p. 56-74, 2013.

JENSEN, M. C.; MECKLING, W. Theory of the firm: managerial behavior, agency costs and capital structure. Journal of Financial Economics. v. 3, n. 4, p. 305-360, 1976.

KHIARI, W.; KARAA, A.; OMRI, A. Corporate governance efficiency: an indexing approach using the stochastic frontier analysis. Corporate Governance. v. 7, n. 2, p. 148-161, 2007.

LA PORTA, R.; LOPEZ-DE-SILANES, F.; SHLEIFER, A. Corporate ownership around the world. Journal of Finance. v. 54, n. 2, p. 471-517, 1999.

LEAL，R. P. C.; CARVALHAL-DA-SILVA，A. L.; VALADARES, S. M. Estrutura de Controle das Companhias Brasileiras de Capital Aberto. Revista de Administração Contemporânea (RAC). v. 6, n. 1, p. 7-18, 2002.

MORCK, R.; SHLEIFER, A.; VISHNY, R. W. Management ownership and market valuation: an empirical analysis. Journal of Financial Economics. v. 20, n.1-2, p. 293-315, 1988. 
OKIMURA, R. T. Estrutura de Propriedade, Governança, Valor e Desempenho das Empresas no Brasil. 2003. 132 f. Dissertação (Mestrado em Administração de Empresas) - Faculdade de Economia, Administração e Contabilidade da Universidade de São Paulo (FEA-USP), São Paulo, 2003.

OKIMURA, R. T.; SILVEIRA, A. D.; ROCHA, K. C. Influência da Concentração de Propriedade e Controle no Valor das Empresas no Brasil. In: IV Encontro Brasileiro de Finanças, Sociedade Brasileira de Finanças, Rio de Janeiro, 2004.

PRESIDÊNCIA DA REPÚBLICA. Casa Civil. Subchefia para Assuntos Jurídicos. Lei no 6.404, de 15 de dezembro de 1976. Dispõe sobre as Sociedades por Ações. Dez. 1976.

PRESIDÊNCIA DA REPÚBLICA. Casa Civil. Subchefia para Assuntos Jurídicos. Lei no 10.303, de 31 de outubro de 2001. Altera e acrescenta dispositivos na Lei no 6.404, de 15 de dezembro de 1976, que dispõe sobre as Sociedades por Ações, e na Lei no 6.385, de 7 de dezembro de 1976, que dispõe sobre o mercado de valores mobiliários e cria a Comissão de Valores Mobiliários. Out. 2001.

SHLEIFER, A.; VISHNY, R. W. A Survey of Corporate Governance. The Journal of Finance. v. 52, n. 2, p. 737-783, 1997.

SILVEIRA, A. D. M. Governança Corporativa e Estrutura de Propriedade: determinantes e relação com o desempenho das empresas no Brasil. 2004. $250 \mathrm{f}$. Tese (Doutorado em Administração) - Faculdade de Economia, Administração e Contabilidade da Universidade de São Paulo (FEA-USP), São Paulo, 2004.

STOCK, J. H.; WATSON, M. W. Econometria. São Paulo: Pearson Addison Wesley, 2004.

VALADARES, S.; LEAL, R. Ownership and control structure of Brazilian companies. Revista Abante. v. 3 , n. 1 , p. $29-56,2000$.

VALOR ECONÔMICO. Balanços globalizados: adoção de normas internacionais de contabilidade tem efeitos distintos entre as empresas. São Paulo, 2011. Disponível em: <http://www.alcantara.pro.br/novo/ index.php?option=com_content\&view $=$ article \&id $=213$ : balancos-globalizados $\&$ catid $=39$ : analise-debalanco\&Itemid=69>. Acesso em: 10 jun. 2012.

ZOLINI, B. Governança Corporativa: Estrutura de Propriedade e o Valor da Empresa. 2008. $67 \mathrm{f}$. Dissertação (Mestrado em Finanças e Economia Internacional) - Fundação Getúlio Vargas (FGV), Rio de Janeiro, 2008. 


\section{APÊNDICE}

Tabela A. Legenda para as variáveis dos modelos de regressão

\begin{tabular}{|c|c|}
\hline Variável & Descrição \\
\hline on_maior & Percentual de capital votante do maior acionista \\
\hline total_maior & Percentual de capital total do maior acionista \\
\hline ontotal_maior & Razão capital votante sobre capital total do maior acionista \\
\hline cont1 & Controlador é indivíduo ou família \\
\hline cont2 & Controlador é investidor institucional \\
\hline cont3 & Controlador é companhia estrangeira \\
\hline cont4 & Controlador é empresa privada nacional \\
\hline cont5 & Controlador é entidade governamental \\
\hline cont6 & Não há controlador definido \\
\hline volatilidade & Volatilidade do retorno das ações da empresa \\
\hline Tamanho & Tamanho da firma \\
\hline crescimento & Crescimento de vendas \\
\hline on_3maiores & Percentual de capital votante dos 3 maiores acionistas \\
\hline total_3maiores & Percentual de capital total dos 3 maiores acionistas \\
\hline ontotal_3maiores & Razão capital votante sobre capital total dos 3 maiores acionistas \\
\hline on_5maiores & Percentual de capital votante dos 5 maiores acionistas \\
\hline total_5maiores & Percentual de capital total dos 5 maiores acionistas \\
\hline ontotal_5maiores & Razão capital votante sobre capital total dos 5 maiores acionistas \\
\hline
\end{tabular}

Fonte: elaborado pelos autores. 